\title{
MODELLING PLANT SPECIES DIVERSITY PATTERN IN A LOCAL ENVIRONMENTAL SPACE
}

\author{
DYAKOV, N. R. \\ Dendrology Department, University of Forestry \\ 10 Kliment Ohridski Blvd. 1797, Sofia, Bulgaria \\ e-mail:nickydyakov@gmail.com \\ (Received $5^{\text {th }}$ Jul 2016; accepted $17^{\text {th }}$ Sep 2016)
}

\begin{abstract}
The loss of biodiversity is a major concern for conservationists and whole human societies these days. Understanding plant species diversity pattern along local environmental gradients can be very useful for undertaking management and conservation measures. Despite the enormous efforts in the last decades, however, unified theory about the plant diversity pattern has not yet emerged. This study tries to model plant species diversity pattern in the context of four local/indirect environmental gradients. Nonparametric correlation and multiple regression methods have been used. Ecological response surfaces of species richness at the two levels of observation showed similar complex distribution in the local environmental space. Vegetation diversity and evenness also had complex pattern with several peaks. Dividing species into growth forms revealed their specific manner of diversity distribution. Plant diversity correlated positively with elevation, habitat dryness, herb stratum cover and mature forest stands. It correlated negatively with slope convexity and inclination, tree stratum cover and early-successional stands. Alien and rare plant species number were also positively correlated with species richness and diversity. $\beta$-diversity variation along moisture gradient was due mainly to herbs. Trees and shrubs showed decreasing $\beta$-diversity along moisture gradient with increasing elevation. $\beta$-diversity along elevational gradient showed no clear trend. Our results support the idea that diversity pattern is much more complicated than previously thought due to the complex interplay between local environmental gradients, vegetation succession and history. Understanding of diversity pattern in the local environmental space will allow resident managers and conservationist to set more specific goals and to take more applicable actions in order to preserve plant diversity in the area for the future generations.
\end{abstract}

Keywords: correlation, regression, GAM, plant diversity, environmental gradients

\section{Introduction}

In the beginning of 21 st century, the loss of biological diversity has become major concern not only to the conservationists but to the whole humanity. Can diminishing biological diversity compromise ecosystem functioning? Do we have enough evidence about the consequences following that process? These and other questions have become a source of concern and controversies but also have let to growing consensus. It turns out that the answer to these questions is not an easy task. The work of numerous researchers until now shows that the ecosystem stability and species diversity have multiple aspects. The relationship stability-diversity depends on which one of their aspects is considered (van der Maarel and Franklin, 2012).

Species diversity can be studied at different scales. Whittaker $(1960,1965,1972)$ proposed several different diversity levels: 1) diversity in a particular sampling plot $(\alpha$-diversity); 2) species composition change along an environmental gradient $(\beta$ diversity); 3) overall landscape diversity ( $\gamma$-diversity). Cody and Diamond (1975) also proposed different levels of diversity: 1) point diversity; 2) sampling plot diversity; 3) diversity change along a local environmental gradient; 4) diversity change along a geographic gradient. However, Whittaker's $\beta$-diversity (Whittaker, 1960) remains one of the simplest to quantify among the highest-level diversity measures because it can 
be measured either as rate of compositional change or environmental gradient length (Peet, 1978b).

Over most landscapes there is obvious regularity of spatial vegetation pattern which is often a consequence of the underlying environmental gradients. A gradient is defined as the change of a particular value of a specific parameter (temperature, soil $\mathrm{pH}$, elevation, soil moisture, species diversity) over space. The term gradient means gradual unidirectional change of the parameter or change in discrete steps over that space (Huston, 1994).

A specific type of gradients are classified as complex because they influence the variation of other resource and regulator gradients (Huston, 1994). They have also been called "factor-complex" (Whittaker, 1956) or "indirect" (Austin and Smith, 1989) gradients. Elevation and habitat moisture are examples of complex gradients. They have no direct effect on plant growth, but they are correlated with various factors that influence growth directly such as precipitation, temperature and solar radiation intensity (Huston, 1994).

Species diversity is measurable attribute of vegetation resulting from the combined effect of processes such as immigration, resource partitioning, competition, adaptation, speciation and extinction. The trade-offs in physiological and life-history characteristics cause the spatial patterns of species composition in response to environmental gradients (Huston, 1994). Measuring the species diversity with the aim of understanding these processes let to implementation of multiple studies whose main goal was documentation of its change along compositional and environmental gradients. However, despite the enormous efforts, unified theory about the plant diversity has not yet emerged (Peet, 1978b).

Studying of plant diversity and its influence requires quantitative measurements. In order to understand species diversity it is needed to determine what factors are correlated with it. The correlations may be positive or negative and may result from direct or complex indirect relationships that demand greater efforts to be clarified. Then, it has to be determined whether the correlations are causal or coincidental by experiments, comparative studies of separate locations, and studies of gradients. However, determining the causes of diversity gradient is extremely difficult (Huston, 1994). The factors that influence this vegetation attribute also have to be understood, thereafter causation relationships, sitting behind statistical ones, can also be tested (van der Maarel and Franklin, 2012). Although statistical analyses can never show causal relationship, they can often show strong correlations of diversity with factors that are marginally responsible for the diversity gradients (Huston, 1994).

Correlation and multiple regression combine field observation of species abundance or presence/absence data with quantitative data of environmental gradients also measured on the field. They produce, statistically tested for accuracy, graphical (biplots, response surfaces, etc.) and numerical models, which can then be used for conservation or management of natural areas. General Additive Models (GAM) (Yee and Mitchell, 1991) are one of the principal statistical techniques used for modeling of vegetation spatial patterns (Guisan and Zimmermann, 2000).

Using correlation and multiple regression analyses, this study tries to model plant diversity and its variation in a constrained environmental space shaped by four important local environmental gradients. We have also attempted to associate/disassociate the emerged knowledge with some well-established classical or more contemporary theories about species diversity pattern. 


\section{Material and methods}

\section{Study site}

The study object was Vitosha Mountain, located in Central Western Bulgaria. It is characterized with compactness and well expressed elevational gradient. The mountain has steep slopes with variable expositions occupied by diverse vegetation with multiple plant species. The current study covers the south slope of the mountain. The GPS coordinates of the studied territory are between N42 $32^{\prime}$ E23 ${ }^{\circ} 09^{\prime}$ and $\mathrm{N} 42^{\circ} 26^{\prime} \mathrm{E} 23^{\circ} 21^{\prime}$. The area covers $118 \mathrm{~km}^{2}$. For details about the studied area refer to (Dyakov, 2012, 2013, 2014).

\section{Sampling}

Sampling strategy was based on gradsect method of Austin and Heyligers (1990). Its advantages are: 1) relatively cheap; 2) highly effective; 3) easy to apply on the field, but requiring experienced workers. During the summers of 2008 and 2009 totally 159 (0.1 ha) samples were taken. The gradsect method design ensures that the gathered samples encompass the greatest variety of environmental condition (elevations, slope inclinations, aspects and slope topographies) throughout the studied territory, covering greatest portion of the realized niche space of most plant species in the area. In all analyses we used species importance value (Curtis, 1959; van der Maarel and Franklin, 2012), which was calculated as mean value of species density, cover and frequency. It is a popular measure of species significance in the sampled vegetation because it combines important aspects of species quantitative occurrence (van der Maarel and Franklin, 2012). Detailed information on the field techniques can be found in previous papers (Dyakov, 2012, 2013, 2014; Dyakov and Zhelev, 2013).

\section{Quantifying the environmental gradients}

Four indirect or factor-complex (Whittaker, 1978) environmental gradients were used - elevation, habitat dryness/moisture, slope inclination and slope convexity. Indirect gradients influence direct gradients, such as temperature and rainfall, which in turn have direct effect on plant growth (Austin, 2005; Austin and Smith, 1989). On a local scale, however, it is recommend measuring and using indirect gradients because they have much more meaningful influence on vegetation pattern and processes (Austin, 2005). Elevation and slope inclination variables were input into analyses with their direct measurements in meters above sea level and degrees, respectively. Habitat dryness and slope topography were quantified using the methodology of Whittaker (1956). For complete procedure on gradient quantification methodology refer to Dyakov (2012).

\section{Species diversity measurement}

Plant community plot diversity ( $\alpha$-diversity) and species turnover along the environmental gradients ( $\beta$-diversity) have been analyzed (Whittaker, 1960). Among the multiple diversity indices in the contemporary literature (Magurran, 2004; Magurran and McGill, 2010) only those meeting the goals and data specificity of this study were used.

Plant species diversity (heterogeneity) (Krebs, 1999) was analyzed in two aspects species richness and evenness. Species richness was measured at two scales - species richness per 0.1 ha sampling plots and mean species richness per $1 \mathrm{~m}^{2}$ sampling 
subplots. On the other hand, species diversity was also represented by the diversity index of Hill (1973) $\mathrm{N}_{2}$ because it is less dependent of the species number in the samples and sample volume (Baev and Penev, 1995). Moreover, it is considered as simple and easy for ecological interpretation (Peet, 1974).

The second aspect of plant diversity, evenness, is defined as a relationship between the diversity index and the maximum value of diversity index which the sample can have, given the same species number (Pielou, 1975). Evenness index of Hill (1973) E' was used because it depends only on the diversity indices and does not depend on the sample volume (Peet, 1974).

Whittaker (1960) defined the term $\beta$-diversity as the species diversity along an environmental or compositional gradient. Thus, $\beta$-diversity was always measured as a rate of species compositional change (Bratton, 1975; Cody and Diamond, 1975; Whittaker, 1960, 1972) or as an environmental gradient length (Gauch and Whittaker, 1972; Moral, 1972; Whittaker, 1972). Using species compositional change rate requires knowledge of the environmental gradient measurement scale which is always arbitrary. Therefore, the gradient length is considered more appropriate measurement as well as easier for interpretation (Peet, 1978a). Gradient length is measured in half-changes. One half-change signifies that distance along the gradient for which given similarity measure (for instance, percent similarity) shows that the species composition has changed with $50 \%$. Because the $\beta$-diversity is a measure for species compositional change along a single gradient, it has been attempted to overcome the influence (variation) of the other environmental gradients. Therefore, trying to separate the effect of elevation from that of habitat dryness, the gathered data were divided into belts (Peet, 1978b). The two leading local environmental gradients (elevation and habitat dryness) were divided into seven equal parts. The lowest limit of the elevation gradient starts from $900 \mathrm{~m}$ and ends up with $2150 \mathrm{~m}$. The habitat dryness gradient parts matched the seven gradient categories described in the cited literature in the Quantifying the environmental gradients section. Gradient lengths were calculated using the Detrended Correspondence Analysis (DCA) algorithm (Hill and Gauch, 1980).

\section{Describing the detailed relationship between species diversity and environmental gradients}

Trying to reveal the detailed relationships between the species diversity and the environmental gradients, nonparametric multiple regression and correlation techniques were used. Because correlated variables were not normally distributed, nonparametric correlation coefficient of Spearman $\left(\mathrm{R}_{\mathrm{s}}\right)$ (Spearman, 1904) was used.

The aim of regression analysis is to describe the dependent variable as a function of one or multiple independent ones. Using regression analyses, dependent variables can be predicted (described) with minimal or less statistical error (Jongman et al., 1995). As a nonlinear regression method, General Additive Models (GAM) were used. The aim of GAM models is to maximize the quality of the dependent variable description which may have various distributions. GAM does so by developing unspecified nonparametric functions of the independent variables which are "connected" with the depended variable by link function. Numerous advantages have made GAM usage in the current ecological studies an indispensable tool (Franklin, 1998; Thuiller et al., 2003; Yee and Mitchell, 1991).

As a better method for visual representation of response surfaces, Locally Weighted Regression (LOESS) (Cleveland and Devlin, 1988) was used. It is one of the 
contemporary modelling techniques intending to overcome some of the drawbacks of the classical ones. LOESS combines the simplicity of the least square methods together with the flexibility of nonlinear regression. This is a procedure for building regression surfaces by multivariate smoothing. Dependent variable is smoothed in a moving fashion as a function of the independent variables analogous to a moving average time series computation (Cleveland and Devlin, 1988).

The most parsimonious regression model was selected with the aim of Akaike Information Criterion (AIC). AIC checks the models for goodness-of-fit and parsimony, and rejects the very complex ones (Carol et al., 2006). According to Thuiller et al. (2003) AIC allows the removal of variable redundancy and multicollinearity problems too.

In all statistical tests the significance level was $\mathrm{P}<0.05$ unless indicated otherwise. The following specialized software products were used: SigmaPlot for Windows, version 12.3 (Systat Software, 2011); CANOCO for Windows, version 4.51 (ter Braak and Šmilauer, 1997-2003); CanoDraw for Windows, version 4.1 (Šmilauer, 1999-2003).

\section{Results}

Plant species richness was calculated at two levels of observation -0.1 ha and $1 \mathrm{~m}^{2}$ (Figure 1), and species diversity and evenness only at 0.1 ha scale (Figure 2). These calculation were based on total sample number of 1590.1 ha plots and $1591 \mathrm{~m}^{2}$ subplots. The tendency of species richness change in the context of elevation, habitat moisture/dryness, slope inclination and convexity is presented on Figure 1. Table 1 shows the statistical significance of chosen models.


Figure 1. Regression response surfaces of species richness in the local environmental space. Elevation = altitude above sea level; Xeric = habitat dryness; Slope = slope inclination; Convexity = slope convexity. Isolines show the predicted species number. (A) Species number per $0.1 \mathrm{ha}$; (B) Mean species number per $1 \mathrm{~m}^{2}$.

Species richness at 0.1 ha scale has several maxima. The first one is located in the most xeric open subalpine habitats at about $1600 \mathrm{~m}$ (Figure 1A). The second one appears in the xeric and subxeric places located at about and below $1000 \mathrm{~m}$. The transitional zone between the forest and open subalpine vegetation (at about $1600 \mathrm{~m}$ ), along the whole length of moisture gradient, also has high species richness. The least 
species richness was found in the submesic habitats, located in the elevational belt of 1200-1300 m where common beech forests (Fagus sylvatica L.) dominate.

Response surface of plant species richness per $1 \mathrm{~m}^{2}$ is shown on Figure 1B. The resemblance between the response surfaces with the previous figure is obvious. Species richness at this scale is least in the submesic beech forests and highest in the xeric habitats at about $1600 \mathrm{~m}$ in the subalpine zone. It is also higher about and below $1000 \mathrm{~m}$ in some mixed oak forests and pine plantations occupying these habitats. With the elevation increase above 1600-1700 $\mathrm{m}$ it abruptly decreases.

Response surfaces of diversity and evenness of local vegetation in the environmental space are shown on Figure 2. The tendency of species diversity response repeats the species richness trend per 0.1 ha.
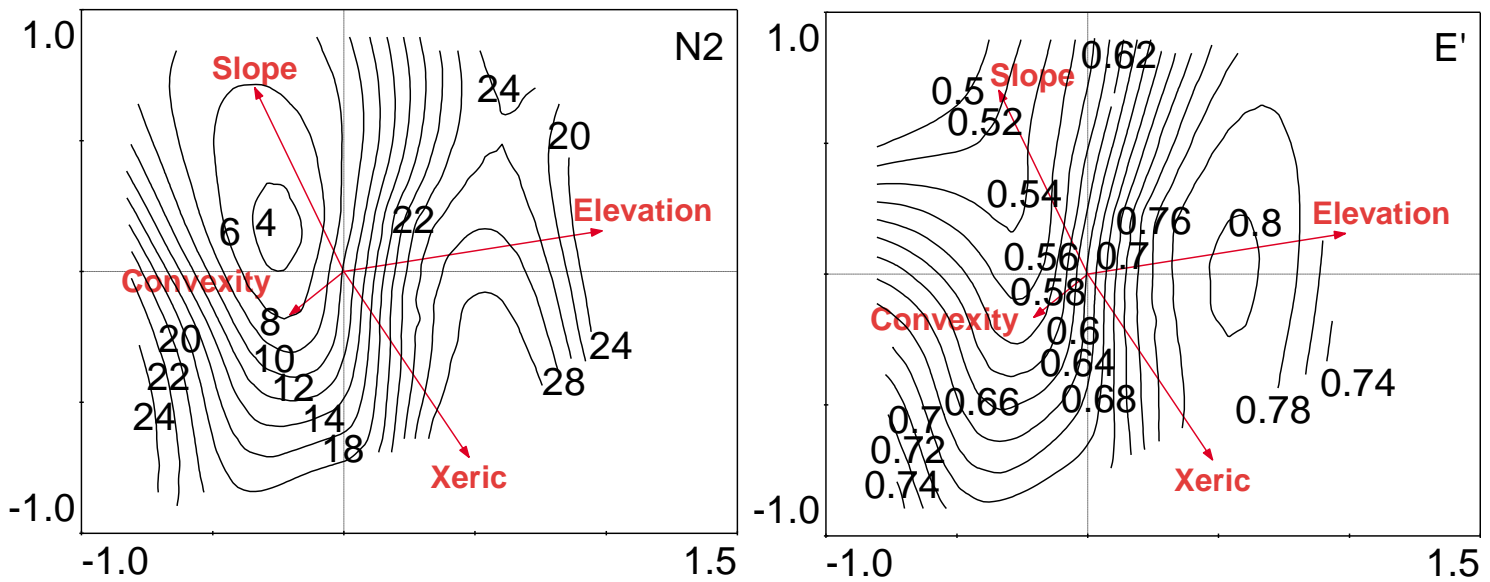

Figure 2. Regression response surfaces of species diversity and evenness in the local environmental space. The names of environmental gradients are the same as in Figure 1. Isolines show the predicted values of the two indices. (N2) Index of species diversity of Hill;

(E') Evenness of Hill.

Table 1. Statistical parameters of used models in Figure 1 and Figure 2. $* * * P<0.001$

\begin{tabular}{lcc}
\hline Variable & Used model & Model significance $(F)$ \\
\hline Species number per 0.1ha & GAM & $13.99 * * *$ \\
Mean species number per 1 ${ }^{2}$ & GAM & $48.95 * * *$ \\
Diversity $\left(\mathrm{N}_{2}\right)$ & GAM & $33.45 * * *$ \\
Evenness $(E ')$ & GAM & $33.04 * * *$ \\
\hline
\end{tabular}

Plant community evenness (Figure 2) has one prominent maximum located in the transitional zone between the forest and subalpine vegetation in the submesic and subxeric habitats at about $1600 \mathrm{~m}$. Second, weaker, mode is seen in the xeric places at about and below $1000 \mathrm{~m}$ where mixed oak forests and Austrian pine (Pinus nigra J.F.Arnold) plantations dominate the vegetation. The beech forests found in the mesic and submesic habitats were least even. Yet, more even seem to be the beech communities from the submesic places, and, with the transition into more mesic sites on steeper slopes, the evenness slowly decreases. With the increasing elevation above 1700 $\mathrm{m}$, vegetation evenness decreases steeply. However, the most abrupt change in all 
diversity and richness indices is seen in the transitional zone between the open subalpine vegetation and forest vegetation, which, most often, is found at about 1500$1600 \mathrm{~m}$, or slightly lower.

Detailed picture of species richness pattern in the local environmental space divided into growth forms is shown on Figure 3.

It is evident that there is obvious similarity between the whole richness pattern and some growth form richness pattern. For example, local richness depression in the beech zone (upper left quadrant of the graphs) is due mainly to the low number of shrubs and perennials. On the other hand, the higher richness of subalpine vegetation is again due mainly to the richness of these two growth forms, but also, to the additional species number of annuals and biennials. Finally, the local vegetation is richest on trees in the low-elevational xeric and subxeric habitats where mixed oak forests and pine plantations dominate (lower left quadrant).

The correlations between the species diversity and richness measurements with the local environmental gradients and vegetation cover are presented in Table 2. All four indices are highly positively correlated with the elevation and moisture gradients but the relationships for species richness per $1 \mathrm{~m}^{2}$ and the evenness are strongest. The opposite trend is found in the relationship with the other two local environmental gradients slope inclination and convexity. All correlations are significant and negative - yet, strongest with the slope inclination.

The right part of Table 2 shows the correlations between the vertical vegetation layers (tree, shrub and herb) and diversity indices. The trend in the tree and herb layers is clear but the shrub layer shows obscure relationships. Tree layer cover is highly negatively correlated with all diversity indices but strongest are the correlations with species richness at $1 \mathrm{~m}^{2}$ and the evenness. Shrub cover is highly positively correlated only with the species richness at 0.1 ha but there are two nonsignificant correlations too. The herb layer correlates highly positively with all $\alpha$-diversity indices.

Table 3 shows the correlations with other important vegetation variables. Most correlations with the trees are nonsignificant except the correlation with species richness at $1 \mathrm{~m}^{2}$ scale. This trend would have stayed blurred if the total species richness had not been divided into growth forms. The correlations with the other growth forms are strongly positive as well as the relationship with the groups of rare and alien plant richness. In other words, the richer the local vegetation on native plant species the richer it is on alien and rare plants too.

The right part of Table 3 shows the correlations between the stem diameter classes (canopy and understory structure) and diversity indices. Most indices are either negatively correlated or show nonsignificant correlation with the early-successional stands where stems with diameters between 1-20 cm dominate. These are mainly beech coppice stands occupying subxeric habitats. On the other hand, forest stands where thicker stems dominate, like some pine plantations and mature beech forests, are positively correlated with diversity index. Whether the relationship is stronger at the coarsest or finest level of observation $\left(0.1\right.$ ha versus $\left.1 \mathrm{~m}^{2}\right)$ is hard to tell from this analysis only. Generally, younger and middle-aged forest stands are poorer on species than mature and old ones, which are more even and diverse too. 

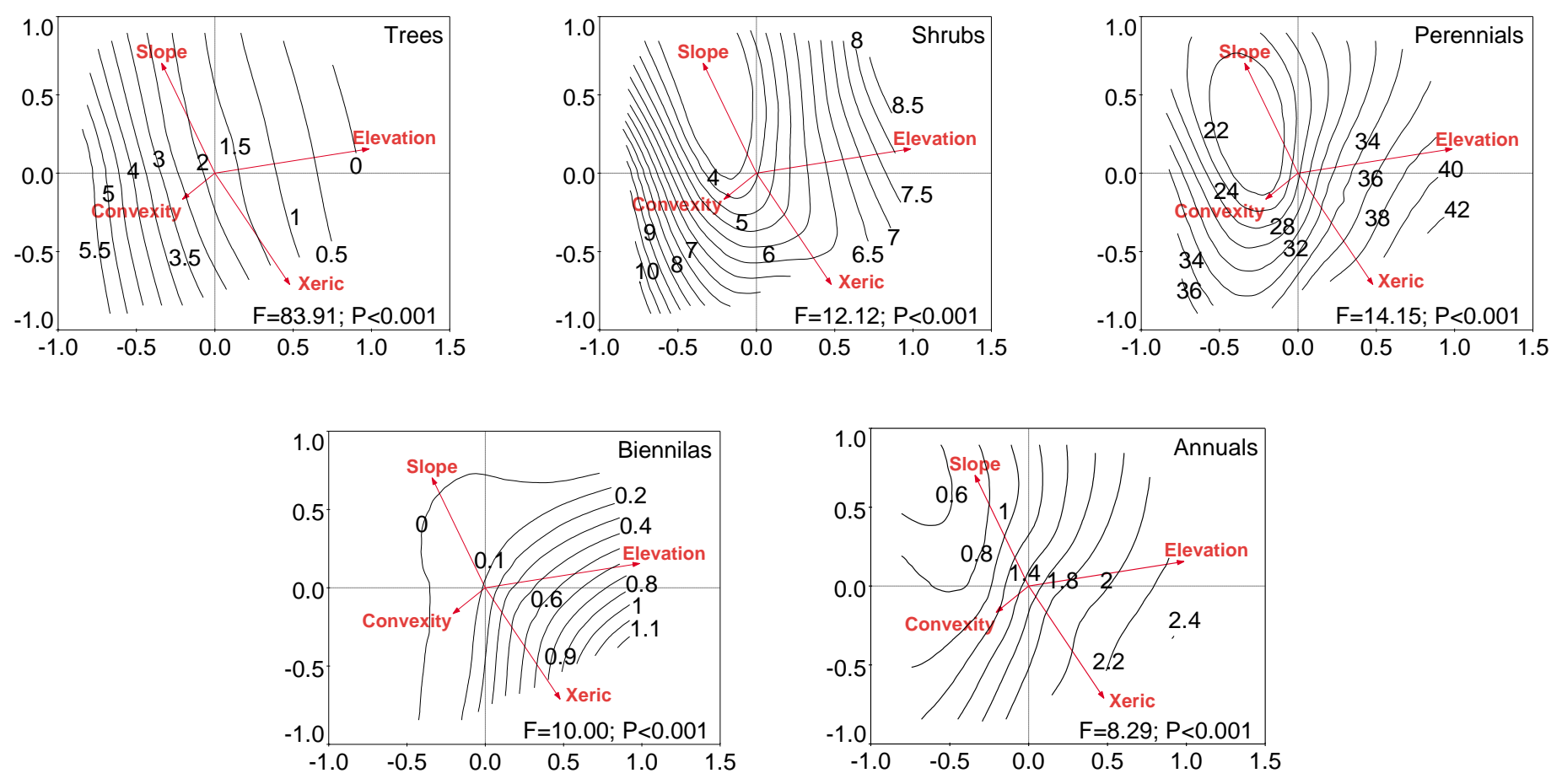

Figure 3. Regression response surfaces of species richness by growth forms in the local environmental space. The names of environmental gradients are the same as in Figure 1. Isolines show the predicted values of species number. Model significance is shown in the lower right part of the graphs. 
Table 2. Spearman correlations between diversity indices, local environmental gradients, and vegetation layer cover $n s=$ not significant; correlation coefficients $> \pm 0.4$ are given in Bold. $* P<0.05 ; * * P<0.01 ; * * * P<0.001$

\begin{tabular}{|c|c|c|c|c|c|c|c|}
\hline \multirow[b]{3}{*}{ Indices } & \multirow{2}{*}{\multicolumn{4}{|c|}{ Environmental gradients }} & \multirow{2}{*}{\multicolumn{3}{|c|}{ Areal cover $(\%)$}} \\
\hline & & & & & & & \\
\hline & Elevation (m) & $\begin{array}{l}\text { Habitat } \\
\text { dryness }\end{array}$ & $\begin{array}{c}\text { Slope } \\
\text { inclination }\left({ }^{\circ}\right)\end{array}$ & $\begin{array}{c}\text { Slope } \\
\text { convexity }\end{array}$ & $\begin{array}{l}\text { Trees } \\
(0.1 \text { ha })\end{array}$ & $\begin{array}{l}\text { Shrubs } \\
\left(100 \mathrm{~m}^{2}\right)\end{array}$ & $\begin{array}{l}\text { Herbs } \\
\left(1 \mathrm{~m}^{2}\right)\end{array}$ \\
\hline Species richness per $0.1 \mathrm{ha}$ & $0.189 *$ & $0.259^{* *}$ & $-0.400 * * *$ & $-0.206^{* *}$ & $-0.703 * * *$ & $0.277 * * *$ & $0.686^{* * *}$ \\
\hline Mean species richness per $1 \mathrm{~m}^{2}$ & $0.466 * * *$ & $0.346^{* * *}$ & $-0.410 * * *$ & $-0.184 *$ & $-0.808 * * *$ & $n s$ & $0.874 * * *$ \\
\hline Species diversity $\left(\mathrm{N}_{2}\right)$ & $0.355^{* * *}$ & $0.337 * * *$ & $-0.441 * * *$ & $-0.232 * *$ & $-0.795 * * *$ & $0.185^{*}$ & $0.808 * * *$ \\
\hline Evenness (E') & $0.422 * * *$ & $0.351 * * *$ & $-0.409 * * * *$ & $-0.260^{* *}$ & $-0.801 * * *$ & $n s$ & $0.818 * * * *$ \\
\hline
\end{tabular}

Table 3. Spearman correlations between diversity indices and some vegetation variables. $n s=$ not significant; correlation coefficients $> \pm 0.4$ are given in Bold. $* P<0.05 ; * * P<0.01 ; * * * P<0.001$

\begin{tabular}{|c|c|c|c|c|c|c|c|c|c|c|c|c|c|c|c|}
\hline \multirow[b]{2}{*}{ Indices } & \multicolumn{5}{|c|}{ Growth form (species number per $0.1 \mathrm{ha}$ ) } & \multirow{2}{*}{$\begin{array}{l}\text { Alien species } \\
\text { number per } 0.1 \text { ha }\end{array}$} & \multirow{2}{*}{$\begin{array}{l}\text { Rare species } \\
\text { number per } 0.1 \text { ha }\end{array}$} & \multicolumn{8}{|c|}{ Stem diameter class $(\mathrm{cm})$ (stem number per $0.1 \mathrm{ha})$} \\
\hline & Trees & Shrubs & Perennials & Biennials & Annuals & & & $1-5$ & $5-10$ & $10-15$ & $15-20$ & $20-25$ & $25-30$ & $30-35$ & $>35$ \\
\hline Species richness per $0.1 \mathrm{ha}$ & $n s$ & $0.762 * * *$ & $0.972 * * *$ & $0.695 * * *$ & $0.523 * * *$ & $0.680 * * *$ & $0.319 * * *$ & $n s$ & $-0.354 * * *$ & $-0.185^{*}$ & $n s$ & $0.308^{* *}$ & $0.221 *$ & $n s$ & $n s$ \\
\hline Mean species richness per $1 \mathrm{~m}^{2}$ & $-0.193^{*}$ & $0.624 * * *$ & $\mathbf{0 .}$ & $* *$ & $* * *$ & $0.506 * * *$ & $* * *$ & $n s$ & $-0.331 * * *$ & $-0.223 *$ & $n s$ & 0.2 & $0.216^{*}$ & $0.208^{*}$ & $n s$ \\
\hline Species diversity $\left(\mathrm{N}_{2}\right)$ & $n s$ & $0.736 * * *$ & $0.930 * * *$ & $0.687 * * *$ & $0.511^{* * *}$ & $0.631 * * *$ & $0.375^{* * *}$ & $n s$ & $-0.389 * * *$ & $n s$ & $n s$ & $0.341 * * *$ & $0.237 *$ & $0.197 *$ & $n s$ \\
\hline Evenness (E') & $n s$ & $0.695 * * *$ & $0.874 * * *$ & $0.628 * * *$ & $0.488 * * *$ & $0.562 * * * *$ & $0.388 * * *$ & $-0.204 *$ & $-0.348 * * *$ & $n s$ & $n s$ & $0.319^{* *}$ & $0.240^{*}$ & $0.200 *$ & $n s$ \\
\hline
\end{tabular}


$\beta$-diversity analysis along the moisture gradient measured in seven elevational belts is presented on Figure 4.

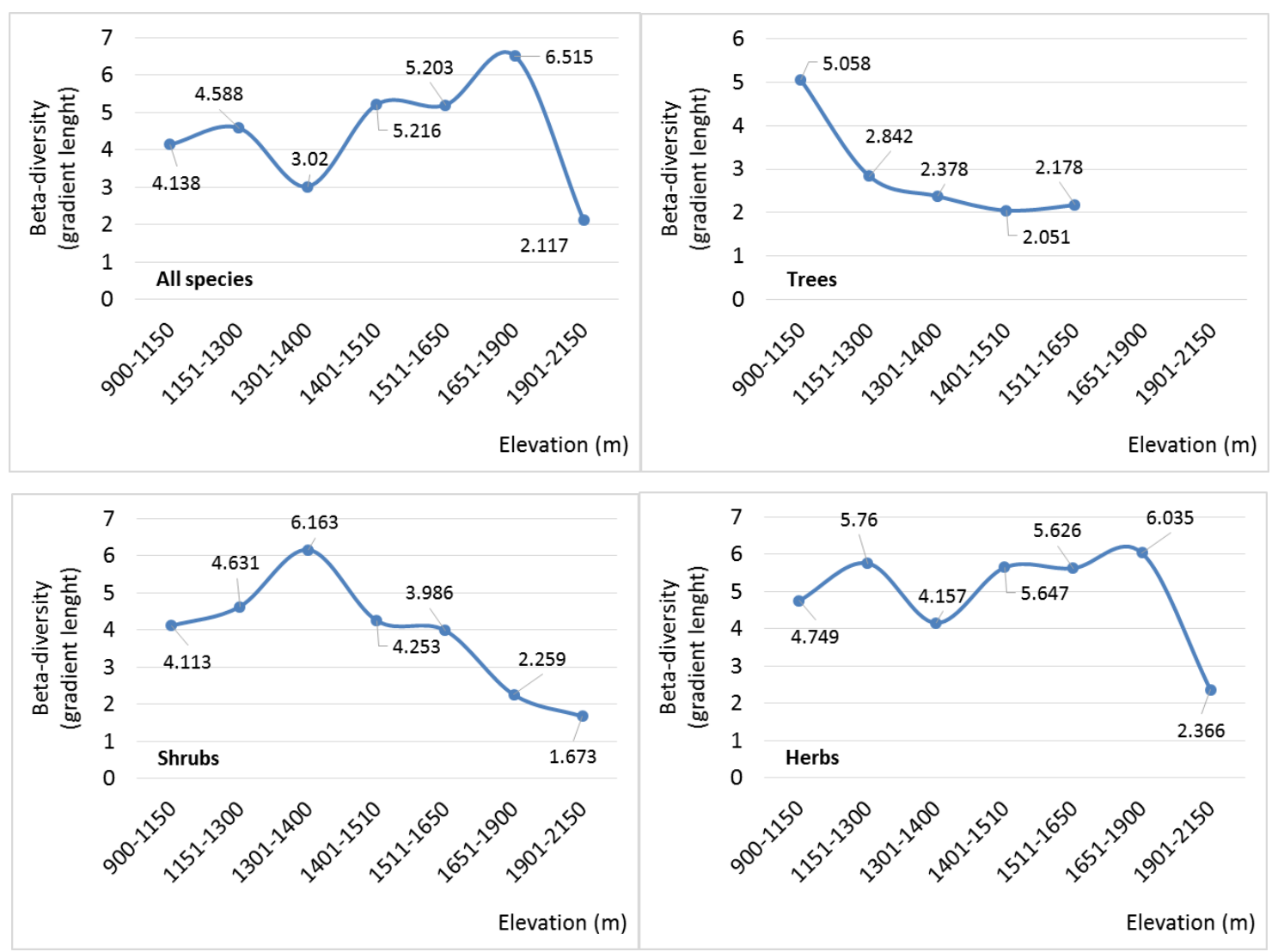

Figure 4. $\beta$-diversity along the moisture gradient. Seven measurements of $\beta$-diversity are shown in different elevation belts. The measurement unit is DCA standard deviation and applies to the gradient length. The overall species compositional change happens in 4 DCA units.

Using the database of all species, we have found highest $\beta$-diversity in habitats at middle to higher elevations (1400-1900 m). Above $1900 \mathrm{~m}$ follows steep decrease. Local depression has been found in the beech forest belt which stretches from about 1300 to $1400 \mathrm{~m}$. Trying to be more specific, we have analyzed the $\beta$-diversity by growth forms. In the tree group, the $\beta$-diversity reaches its maximum in the low-elevational belt, between $900-1150 \mathrm{~m}$. It is followed by a gradual decrease until reaching its minimal values in the zone between 1400-1650 m. Above that elevation in the studied area, tree species can hardly be found. The shrubs have their maximum located at the middle elevations (1300-1400) where their lower species richness in the beech belt (see Figure 3) is not an obstacle for their higher $\beta$-diversity. This is probably due to the presence of pine plantations across that area where the shrub layer is very well represented. Herbs show highly similar curve shape to all species' curve which leaves no doubt that the highest contribution to the $\beta$-diversity trend along the moisture gradient is mainly due to them. The herbs show highest $\beta$-diversity in the subalpine habitats, extending across middle to higher elevations (1400-1900 m). There is second mode in the mixed oak forest belt and pine plantation belt, as well as a local depression in the beech forest belt, occupying elevations between 1300 and $1400 \mathrm{~m}$. 
$\beta$-diversity trend along the elevational gradient measured in seven moisture segments is shown on Figure 5.

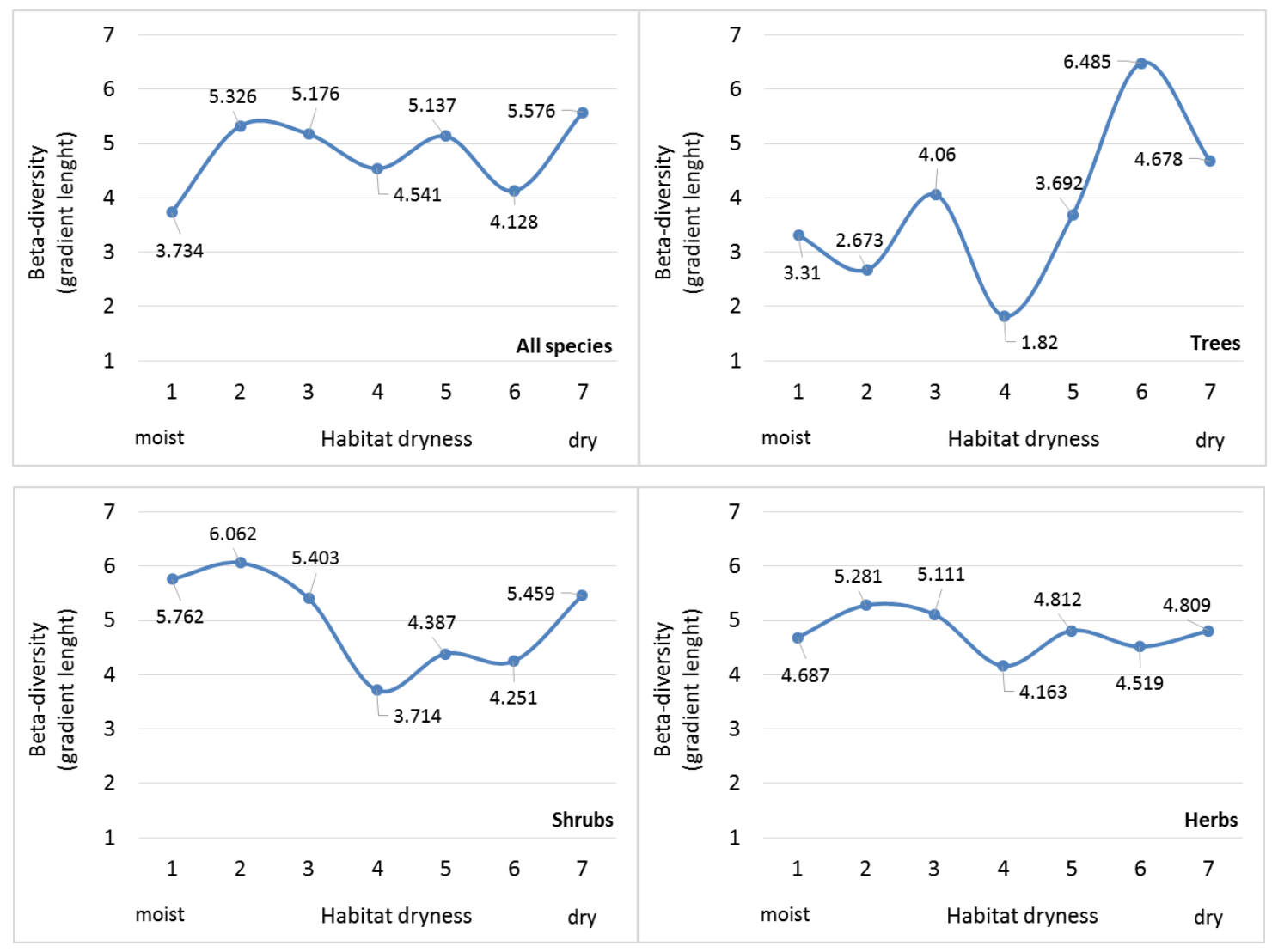

Figure 5. $\beta$-diversity along the elevation gradient. Seven measurements of $\beta$-diversity are shown in different moisture gradient belts from the moistest to the driest habitats.

With the exception of the minimal value in the most mesic sites, the lowest $\beta$ diversity of all species, taken together, is found in the subxeric habitats. This trend is somehow obscured by the successive changes of the index values in the opposite directions across the whole spectrum of moisture segments. The trees' $\beta$-diversity is highest in the subxeric and xeric sites which is probably due to the presence of mixed oak forest there and their higher tree species richness. The shrubs show the opposite trend. Their highest $\beta$-diversity is located in the moistest gradient segments (occupied mainly by beech forests). The herbs almost repeat the trend of all species but with more weakly expressed successive changes along the moisture gradient segments. Their maximal $\beta$-diversity is found in the submesic habitats. Here, similarly to some former cases, the probable cause for this trend is the more intense competition in the favorable sites leading to ecological niche compression which leads to higher $\beta$-diversity.

\section{Discussion}

This study tried to model plant species richness and diversity in the context of four local environmental gradients (the local environmental space) - elevation, habitat moisture, slope inclination and slope convexity. It also attempts to juxtaposition its 
findings to the accumulated so far knowledge, concerning species richness and diversity pattern along environmental gradients, and to bring new insights into the species diversity pattern understanding.

\section{$\alpha$-diversity relationship with moisture gradient}

$\alpha$-diversity can change systematically along the environmental gradients (Gauch and Whittaker, 1976) but this trend cannot be easily explained. It can also demonstrate variable patterns along habitat moisture gradient (Minchin, 1989).

It has been reported that the $\alpha$-diversity reaches its maximum in the most mesic part of moisture gradient (Daubenmire and Daubenmire, 1968; Glenn-Lewin, 1975; Terborgh, 1973) or has its optimum in the middle parts of the gradient (Auclair and Goff, 1971; Monk, 1965, 1967; Whittaker, 1956; Whittaker and Niering, 1965). Furthermore, most xeric habitats have been documented to be least diverse (Daubenmire and Daubenmire, 1968; Moral, 1972) but the opposite trend has also been observed, i.e. increasing diversity with the transition from wet (with temperate climate) to dry (with variable climate) habitats (Whittaker, 1960). Finally, there is evidence that species diversity of different growth forms can vary in different (opposite) manner along the productivity gradient - for example, decreasing of tree diversity versus increasing grass and herb diversity (Huston, 1994). Similar pattern can be witnessed in our results, where all growth forms, except trees, showed increasing diversity along the decreasing moisture gradient (Figure 3). It also became clear that total species diversity has its maximum in the xeric end of moisture gradient in both forest and open subalpine vegetation. For the forest communities, explanation of this phenomenon can be sought, as already proposed by some previous researches (Auclair and Goff, 1971; Moral, 1972; Peet, 1978b), in the more open forest canopy in these sites, letting greater quantities of sunlight to reach the forest floor, thereby giving chance for development of more abundant and diverse herb layer. The greater diversity of the open subalpine communities, however, can be explained with the Grime's (Grime, 1973; Grime, 2006) hypothesis which suggests that the $\alpha$-diversity should have unimodal shape of distribution along the stress/productivity gradient (Al-Mufti et al., 1977; Tilman, 1982) with maximum diversity under moderate stress/productivity. In our case, the cause of this moderate stress/productivity is the summer and autumn drought (the studied area is under rain shadow cast by the higher northwestern mountainous ridge) which does not allow one or few dominant plant species to outcompete the rest species and to monopolize the habitat.

The relationship between the competitive exclusion rate and diversity pattern is in the basis of the dynamic equilibrium theory (Huston and DeAngelis, 1994), according to which, the rate of competitive exclusion is faster in the most favorable habitats. Austin and Smith (1989) speculated that species richness should take bimodal shape along both, resource-gradients and regulator gradients, and its modes should appear in the extreme parts of the gradients. Our results partly supported the later hypothesis because we have found highest diversity under extreme drought. On the other hand, Peet (1978b) discusses and concludes that generalization about the relationship between the diversity and moisture gradient is not possible, and explanation of the diversity variation along environmental gradients should be sought in the relationship diversityelevation. He also acknowledges that the more moderate (in terms of their habitat conditions) and most widely distributed plant communities are distinguished with least 
diversity (for example, dense even-aged forests) in contrast to vegetation occupying the more extreme sites, having highest diversity.

\section{a-diversity relationship with elevation}

The trend of species diversity change along the elevational gradient is unclear. There is evidence that diversity decreases along the elevational gradient (Reed, 1969; Stohlgren, 2007; Whittaker, 1956; Yoda, 1967). However, in the dry regions it often reaches its maximum at middle elevation (Daubenmire, 1970; Daubenmire and Daubenmire, 1968; Gradstein et al., 1989; Peet, 1978b; Tryon et al., 1989; Whittaker and Niering, 1965, 1975). This trend is explained with the higher richness of herbs. They reach local maximum in sites where the tree stratum is poorly developed and the canopy is more open (Daubenmire and Daubenmire, 1968; Moral, 1972; Peet, 1978b; Stohlgren, 2007; Whittaker and Niering, 1965). It has been also shown (Whittaker, 1960) that the plant diversity decreased with increasing elevation, but only for the tree growth form, while the herb diversity showed the opposite trend. Tree richness approached its maximum at middle elevation followed by a decrease in the highest mountainous habitats. Generally, negative relationship between tree and the other vegetation strata have been established (Whittaker, 1960). Our results concerning the total species richness change along the elevational gradient showed increasing richness with increasing elevation, but this trend is obscured by the complex species richness pattern, resulting from the use of several local gradients altogether. The regression analysis, for example, showed two maxima. The first one was located in the xerophilous forests at lower elevation and the second one was centered in the transitional zone (ecotone) at middle elevation. It is considered that multiple-gradient analyses represent a closer-to-the-reality picture, because of the underlining interaction between them, compared to single-gradient ones proposed in earlier studies. On the other hand, our growth form diversity analysis completely supports the Whittaker's (Whittaker, 1960) observation of the negative relationship between tree and understory strata.

It is known that the diversity is relatively high in the transitional sites (ecotones), where forest vegetation changes into open or scrubland vegetation (Peet, 1978b). This trend is fully supported by our results too. We have found higher diversity in the transitional zones between the forest and subalpine vegetation along the whole length of moisture gradient, despite that, its diversity mode was in its driest part. This is probably due to saturation of ecotones with plant species adapted to survive in the two vegetation types in close proximity (forest and open herb and shrub vegetation), and to the higher heterogeneity of these habitats, giving chance to more plant species to establish and persist in the specific microhabitats of that area.

\section{$\alpha$-diversity relationship with vegetation succession}

Plant diversity interpretation is additionally complicated due to interrelationship between successional and environmental gradients. As a surrogate of the successional gradient we used the quantitative distribution of stem diameter classes in the environmental space (on the chronosequence-principle grounds) (Pickett, 1989). It has been theoretically suggested (Odum, 1969) and empirically/experimentally observed (Bazzaz, 1975; Burrows, 1990; Monk, 1965, 1967; Tilman, 1988) that species diversity increases during the successional development of stands, reaching an asymptote at the final steady-state phase. It has also been reported that diversity 
increases reaching a peak in the later successional phases, afterwards, due to loss of early-successional species, it slowly decreases with the approaching of "climax" phase (Auclair and Goff, 1971; Whittaker, 1972). Finally, there are observations showing that plant diversity was highest in the early successional stage after which it abruptly declined (Houssard et al., 1980; Whittaker, 1970). Our results support the second hypothesis because we have found that the least diverse stands were those where thinner stems dominated $(5-10 \mathrm{~cm})$. Then, the plant diversity increased and reached its maximum in the mature stands, followed by a new decrease in the oldest forests. However, making such interpretations should be done carefully, because successional forest development is highly influenced by the environmental gradients and can have significant deviations from this tendency in the different habitats. According to Peet (1978b), in the xeric habitats, as well as in the transitional sites at higher elevations, species diversity increases slowly until the steady-state phase, or increases to a moderate, early peak, after which it decreases smoothly with the stand development. The unfavorable conditions in these habitats hamper the seedlings' establishment and growth, leading to slower stand development, in contrast to the favorable sites, where stand development is much more accelerated. As a result of the delayed stand development in the unfavorable sites, the vegetation occupying them rarely, or even never, reach enough canopy closure to prevent understory survival and regeneration, thus, leading to their higher species diversity (Peet, 1978b; Whittaker, 1970).

\section{$\alpha$-diversity relationship with vegetation history}

Finally, the interpretation of species diversity should always be placed in the context of habitat history, i.e. what natural and anthropogenic disturbances have taken place in the past (Peet, 1978b). The relatively low diversity of the beech forests in our study is also indication of their preservation from such events in the near past and the present. The emergence and maintenance of intermediate-level natural and anthropogenic disturbances in these forests will probably increase their species diversity but it could also lead to their degradation. The location of the mixed oak forests and pine plantations close to the human settlements suggests their substantial disturbance pressure. Along with the other factors, this unquestionably contributes for their higher plant species diversity.

It can be summarized that the adequate interpretation of vegetation's $\alpha$-diversity should be done in the context of environmental and successional gradients, as well as the disturbance history of the area. Moderate stress and disturbance frequency often lead to increased diversity. When the diversity is very high and the habitat conditions are far from optimal, though, the crucial factor is the relaxed competition from the dominant plant species in the area (Peet, 1978b).

\section{$\beta$-diversity}

The $\beta$-diversity is conceptually important because it is directly connected to the concept of ecological niche along the environmental gradients (Peet, 1978b). The favorable site conditions and their predictability should lead to niche compression and higher $\beta$-diversity. On the contrary, the frequent fluctuations and intense ecological stress should lead to low $\beta$-diversity (Cody and Diamond, 1975; MacArthur, 1970; Macarthur and Levins, 1967; May, 2001; Whittaker, 1972). 
The higher $\beta$-diversity at low elevations is due to the variable site conditions, compared to the more uniform conditions in the highest mountainous parts (Peet, 1978b). In our case, though, this applies only to the tree and shrub growth forms. The harsh climatic conditions at higher elevation do not allow greater number of trees and shrubs to survive and adapt, which leads to their lower $\beta$-diversity. In contrast, the herbs are most abundant and diverse in the open subalpine habitats, excepting the highest mountainous parts (above $1900 \mathrm{~m}$ ), where again, few herb species can adapt and assume dominance, which leads to very low $\beta$-diversity. On the other hand, in the lowelevational (favorable) mesic habitats, herbs are outcompeted by the dominant shrubs and trees. In the open subalpine habitats the competition is also intense but mainly between herbs and some dwarf shrub species, which cannot outcompete them, leading to their highest $\beta$-diversity. The highest mountainous parts have least $\beta$-diversity not only because of the harsh conditions there but also because of their isolation and poor species pool of potential colonizers (Peet, 1978b). Another potential reason is the loss of species during the last ice age - the so called "relaxation" process (Peet, 1978b).

Whittaker (1960) has found that the rate of $\beta$-diversity change along the moisture gradient increases from tree to herb species. This is confirmed in our results too. However, this tendency cannot be confirmed for the elevational gradient. It was also found (Whittaker, 1960), that $\beta$-diversity of forest vegetation decreases with elevation but that trend was not proved for all vegetation strata and all elevational belts. Similar trend is evident in our results too. It is especially well expressed for the tree stratum. Shrubs show similar pattern with the exception of the local peak in the 1300-1400 m elevational segment. Herbs, on the other hand, show exactly the opposite tendency. The most noticeable similarity between our and Whittaker's (Whittaker, 1960) results concerns the parallel change of $\alpha$ - and $\beta$-diversity. The increase and decrease of the two indices happens analogously along the whole spectrum of environmental site conditions. It was suggested (Whittaker, 1960), that the cause of this phenomenon is the relatively abrupt change of site conditions in the adjacent habitats. We can add that this is the probable cause of the higher $\beta$-diversity in the transitional zone between the forest and subalpine vegetation.

The difference in the $\beta$-diversity along the moisture gradient in the various plant communities is caused by the different environmental conditions on the slopes with different exposition (Whittaker and Niering, 1965). For example, the difference between southwest-facing slopes and the deep moist ravines in their microclimate is much more evident in the continental climate of the studied territory. The lower $\beta$-diversity of the shrubs and herbs at the mountainous base (for instance, in the mixed oak forests) can be explained with the lack of one or few strong competitors which allows more extended ecological niches along the moisture gradient, hence lower $\beta$-diversity. As already mentioned, these communities are characterized with intense human disturbance (logging, livestock grazing) which additionally leads to extended ecological niches via the maintenance of more open forest canopy. For example, the moderate, or even intensive, but not extremely intensive grazing, let to increased $\alpha$-diversity (Naveh and Whittaker, 1980). This is the result from the extended period of coevolution during which the plant species have adapted to this type of disturbance. For thousands of years, the plant species adapted to grazing disturbance, have saturated these habitats leading to increased $\alpha$-diversity and decreased $\beta$-diversity (Naveh and Whittaker, 1980), which can be offered as explanation for the discrepancy between the greater $\alpha$-diversity and the lower $\beta$-diversity that we have found. 
In conclusion, it should be stated that plant $\alpha$-diversity shows complex pattern in the context of several local environmental gradients compared to the single-gradient analyses from the past documenting unimodal or bimodal curve shapes. It is considered that analyzing plant diversity along several environmental gradients altogether gives more realistic picture of this natural phenomenon. Dividing species diversity into growth forms can bring additional information about their contribution to the total plant diversity pattern. The $\beta$-diversity modelling can reveal information about plant species competition in the local environmental space as well as information about the disturbance regime and history of the vegetation.

Acknowledgements. The author is thankful to Eli Pavlova and Dragomir Zahariev for their help on the field. This study was supported by University of Forestry's (Sofia, Bulgaria) Grand \#47/1304, 2009.

\section{REFERENCES}

[1] Al-Mufti, M.M., Sydes, C.L., Furness, S.B., Grime, J.P., Band, S.R. (1977): A Quantitative Analysis of Shoot Phenology and Dominance in Herbaceous Vegetation. Journal of Ecology 65: 759-791.

[2] Auclair, A.N., Goff, F.G. (1971): Diversity Relations of Upland Forests in the Western Great Lakes Area. - The American Naturalist 105: 499-528.

[3] Austin, M.P. (2005): Vegetation and environment: discontinuities and continuities. - In: Van der Maarel, E. (Ed.) Vegetation ecology. Blackwell Publishing, pp. 52-84.

[4] Austin, M.P., Heyligers, P. (1990): New approach to vegetation survey design: gradsect sampling. - In: Margules, C., Austin, M. (Eds.) Nature Conservation: Cost Effective Biological Surveys and Data Analysis. CSIRO, Canberra, Australia, pp. 31-36.

[5] Austin, M.P., Smith, T.M. (1989): A New Model for the Continuum Concept. - Vegetatio 83: 35-47.

[6] Baev, P., Penev, L. (1995): BIODIV. Program for Calculating Biological Diversity Parameters, Similarity, Niche Overlap, and Cluster Analysis, Version 5.1. - Pensoft, Sofia.

[7] Bazzaz, F.A. (1975): Plant Species Diversity in Old-Field Successional Ecosystems in Southern Illinois. - Ecology 56: 485-488.

[8] Bratton, S.P. (1975): A Comparison of the Beta Diversity Functions of the Overstory and Herbaceous Understory of a Deciduous Forest. - Bulletin of the Torrey Botanical Club 102: 55-60.

[9] Burrows, C. (1990): Processes of vegetation change, Processes of Vegetation Change. Springer Netherlands, pp. 359-419.

[10] Carol, J., Benejam, L., Alcaraz, C., Vila-Gispert, A., Zamora, L., Navarro, E., Armengol, J., García-Berthou, E. (2006): The effects of limnological features on fish assemblages of 14 Spanish reservoirs. - Ecology of Freshwater Fish 15: 66-77.

[11] Cleveland, W.S., Devlin, S.J. (1988): Locally Weighted Regression: An Approach to Regression Analysis by Local Fitting. - Journal of the American Statistical Association 83: 596-610.

[12] Cody, M.L., Diamond, J.M. (1975): Ecology and Evolution of Communities. - Belknap Press of Harvard University Press.

[13] Curtis, J.T. (1959): The Vegetation of Wisconsin: An Ordination of Plant Communities. University of Wisconsin Press.

[14] Daubenmire, R. (1970): Steppe vegetation of Washington. - Washington State University, Washington. 
[15] Daubenmire, R., Daubenmire, J.B. (1968): Forest vegetation of Eastern Washington and Northern Idaho, Washington.

[16] Dyakov, N. (2012): Classification of forest vegetation on the south slope of Vitosha Mountain, Western Bulgaria. - Forestry Ideas 43: 57-77.

[17] Dyakov, N. (2013): Successional Pattern, Stand Structure and Regeneration of Forest Vegetation According to Local Environmental Gradients. - Ecologia Balkanica 5: 69-85.

[18] Dyakov, N. (2014): Gradient analysis of vegetation on the south slope of Vitosha mountain, Southwest Bulgaria. - Applied Ecology and Environmental Research 12: 1003-1025.

[19] Dyakov, N., Zhelev, P. (2013): Alien species invasion and diversity of riparian forest according to environmental gradients and disturbance regime. - Applied Ecology and Environmental Research 11: 249-272.

[20] Franklin, J. (1998): Predicting the distribution of shrub species in southern California from climate and terrain-derived variables. - Journal of Vegetation Science 9: 733-748.

[21] Gauch, H.G. Jr., Whittaker, R.H. (1972): Coenocline Simulation. - Ecology 53: 446-451.

[22] Gauch, H.G. Jr., Whittaker, R.H. (1976): Simulation of Community Patterns. -Vegetatio 33: $13-16$.

[23] Glenn-Lewin, D.C. (1975): Plant species diversity in ravines of the southern Finger Lakes region, New York. - Canadian Journal of Botany 53: 1465-1472.

[24] Gradstein, S.R., Van Reenen, G.B.A., Griffin, D. (1989): Species richness and origin of the bryophyte flora of the Colombian Andes. - Acta Botanica Neerlandica 38: 439-448.

[25] Grime, J.P. (1973): Competitive Exclusion in Herbaceous Vegetation. - Nature 242: 344-347.

[26] Grime, J.P. (2006): Plant Strategies, Vegetation Processes, and Ecosystem Properties. Wiley.

[27] Guisan, A., Zimmermann, N.E. (2000): Predictive habitat distribution models in ecology. - Ecological Modelling 135: 147-186.

[28] Hill, M.O. (1973): Diversity and Evenness: A Unifying Notation and Its Consequences. Ecology 54: 427-432.

[29] Hill, M.O., Gauch, H.G. (1980): Detrended Correspondence Analysis: An Improved Ordination Technique. - Vegetatio 42: 47-58.

[30] Houssard, C., Escarré, J., Bomane, F. (1980): Development of species diversity in some mediterranean plant communities. - Vegetatio 43: 59-72.

[31] Huston, M.A. (1994): Biological Diversity: The Coexistence of Species. - Cambridge University Press.

[32] Huston, M.A., DeAngelis, D.L. (1994): Competition and Coexistence: The Effects of Resource Transport and Supply Rates. - The American Naturalist 144: 954-977.

[33] Jongman, R.H.G., ter Braak, C.J.F., van Tongeren, O.F.R. (1995): Data Analysis in Community and Landscape Ecology. - Cambridge University Press.

[34] Krebs, C.J. (1999): Ecological Methodology. - Benjamin/Cummings.

[35] MacArthur, R. (1970): Species packing and competitive equilibrium for many species. Theoretical Population Biology 1: 1-11.

[36] MacArthur, R., Levins, R. (1967): The Limiting Similarity, Convergence, and Divergence of Coexisting Species. - The American Naturalist 101: 377-385.

[37] Magurran, A.E. (2004): Measuring Biological Diversity. - Wiley.

[38] Magurran, A.E., McGill, B.J. (2010): Biological Diversity: Frontiers in Measurement and Assessment. - OUP Oxford.

[39] May, R.M. (2001): Stability and Complexity in Model Ecosystems. - Princeton University Press.

[40] Minchin, P.R. (1989): Montane Vegetation of the Mt. Field Massif, Tasmania: A Test of Some Hypotheses about Properties of Community Patterns. - Vegetatio 83: 97-110.

[41] Monk, C.D. (1965): Southern Mixed Hardwood Forest of Northcentral Florida. Ecological Monographs 35: 336-354. 
[42] Monk, C.D. (1967): Tree Species Diversity in the Eastern Deciduous Forest with Particular Reference to North Central Florida. - The American Naturalist 101: 173-187.

[43] Moral, R.D. (1972): Diversity Patterns in Forest Vegetation of the Wenatchee Mountains, Washington. - Bulletin of the Torrey Botanical Club 99: 57-64.

[44] Naveh, Z., Whittaker, R.H. (1980): Structural and floristic diversity of shrublands and woodlands in Northern Israel and other Mediterranean areas. - Vegetatio 41: 171-190.

[45] Odum, E.P. (1969): The Strategy of Ecosystem Development. - Science 164: 262-270.

[46] Peet, R. (1978a): Forest vegetation of the Colorado Front Range: Patterns of species diversity. - Vegetatio 37: 65-78.

[47] Peet, R.K. (1974): The Measurement of Species Diversity. - Annual Review of Ecology and Systematics 5: 285-307.

[48] Peet, R.K. (1978b): Latitudinal Variation in Southern Rocky Mountain Forests. - Journal of Biogeography 5: 275-289.

[49] Pickett, S.A. (1989): Space-for-Time Substitution as an Alternative to Long-Term Studies. - In: Likens, G. (Ed.) Long-Term Studies in Ecology. Springer New York, pp. 110-135.

[50] Pielou, E.C. (1975): Ecological diversity. - Wiley.

[51] Reed, R. (1969): A study of forest vegetation in the Wind River Mountains, Wyoming. Ph.D. thesis - Wash. State Univ., Pullman.

[52] Šmilauer, P. (1999-2003): CanoDraw for Windows, 4.1 ed. - Glenn Randers-Pehrson.

[53] Spearman, C. (1904): The Proof and Measurement of Association between Two Things. The American Journal of Psychology 15: 72-101.

[54] Stohlgren, T.J. (2007): Measuring Plant Diversity: Lessons from the Field. - Oxford University Press, USA.

[55] Systat Software, I. (2011): SigmaPlot for Windows, 12.3 ed.

[56] ter Braak, C., Šmilauer, P. (1997-2003): CANOCO for Windows, 4.51 ed. - Biometrics, Plant Research International.

[57] Terborgh, J. (1973): On the Notion of Favorableness in Plant Ecology. - The American Naturalist 107: 481-501.

[58] Thuiller, W., Araújo, M.B., Lavorel, S. (2003): Generalized Models vs. Classification Tree Analysis: Predicting Spatial Distributions of Plant Species at Different Scales. Journal of Vegetation Science 14: 669-680.

[59] Tilman, D. (1982): Resource Competition and Community Structure. - Princeton University Press.

[60] Tilman, D. (1988): Plant Strategies and the Dynamics and Structure of Plant Communities. - Princeton University Press.

[61] Tryon, R.M., Stolze, R.G., Smith, A.R., Mickel, J.T., Moran, R.C., Hickey, R.J., Oellgaard, B. (1989): Pteridophyta of Peru. - Field Museum of Natural History, Chicago.

[62] van der Maarel, E., Franklin, J. (2012): Vegetation Ecology. - Wiley.

[63] Whittaker, R.H. (1956): Vegetation of the Great Smoky Mountains. - Ecological Monographs 26: 2-80.

[64] Whittaker, R.H. (1960): Vegetation of the Siskiyou Mountains, Oregon and California. Ecological Monographs 30: 279-338.

[65] Whittaker, R.H. (1965): Dominance and Diversity in Land Plant Communities. - Science 147: 250-260.

[66] Whittaker, R.H. (1970): Communities and ecosystem. - Macmillan.

[67] Whittaker, R.H. (1972): Evolution and Measurement of Species Diversity. - Taxon 21: 213-251.

[68] Whittaker, R.H. (1978): Ordination of plant communities. - In: Whittaker, R.H. (Ed.) Handbook of vegetation science, Junk, The Hague.

[69] Whittaker, R.H., Niering, W.A. (1965): Vegetation of the Santa Catalina Mountains, Arizona: A Gradient Analysis of the South Slope. - Ecology 46: 429-452. 
[70] Whittaker, R.H. \& W.A., Niering. (1975): Vegetation of the Santa Catalina Mountains, Arizona. V. Biomass, Production, and Diversity along the Elevation Gradient. - Ecology 56: 771-790.

[71] Yee, T.W., Mitchell, N.D. (1991): Generalized Additive Models in Plant Ecology. Journal of Vegetation Science 2: 587-602.

[72] Yoda, K. (1967): A preliminary survey of the forest vegetation of Eastern Nepal. Journal of the College of Arts and Sciences, Chiba University 5: 99-140, 118p. 